\title{
Solitary fibrous tumor - clinicopathologic, immunohistochemical and molecular analysis of 28 cases
}

Rob JC Vogels ${ }^{1 *}$, Myrella Vlenterie ${ }^{2}$, Yvonne MH Versleijen-Jonkers $^{2}$, Emiel Ruijter $^{3}$, Elise M Bekers ${ }^{1}$, Marian AJ Verdijk' , Monique M Link', Johannes J Bonenkamp ${ }^{4}$, Winette TA van der Graaf ${ }^{2}$, Pieter J Slootweg ${ }^{1}$, Albert JH Suurmeijer ${ }^{5}$, Patricia JTA Groenen ${ }^{1}$ and Uta Flucke ${ }^{1}$

\begin{abstract}
Background: Solitary fibrous tumor is a mesenchymal tumor of fibroblastic type, which can affect any region of the body. Recently, a recurrent gene fusion NAB2-STAT6 has been identified as molecular hallmark. The NAB2-STAT6 fusion leads to EGR1 activation and transcriptional deregulation of EGR1-dependent target genes and is a driving event in initiation of SFT. In this study, we report the clinicopathologic and RT-PCR findings and evaluated expression of STAT6 and EGR1 protein in a cohort of 28 SFTs.

Methods: 28 patients with a median age of 54 years were included with SFTs originating at different sites, most occurring in the lung and pleura (9,32\%), 5 in soft tissues of the lower extremities (18\%) and 5 in the head and neck (18\%). For detection of the NAB2-STAT6 fusion gene, RT-PCR was performed using RNA extracted from formalin-fixed and paraffin-embedded tissues. Immunohistochemistry was performed on all cases with antibodies against STAT6 and EGR1.
\end{abstract}

Results: All patients were treated by surgery, 3 with adjuvant chemo- or radiotherapy. Follow-up data of 18 patients could be obtained of which 2 patients died of metastatic disease 13 months and 52 years after first diagnosis. Sixteen patients have no evidence of disease with a median follow up of 29.5 months (range $7-120$ months). NAB2-STAT6 fusion transcripts were found in 19/28 cases (68\%). The most common fusion was between NAB2 exon 4 and STAT6 exon $3(11 / 19,58 \%)$, mainly occurring in pleuropulmonary lesions. All cases showed strong nuclear expression of STAT6 (28/28, 100\%) while EGR1 showed low-level variable nuclear expression in all samples, comparable with the EGR1 expression results of the control group.

Conclusions: The identification of the NAB2-STAT6 fusion in SFTs can provide important diagnostic information, especially in cases with aberrant morphology or when biopsy material is limited. STAT6 immunohistochemistry is another useful tool in diagnosing SFT. EGR1 immunohistochemistry indicates low-level protein expression in accordance with EGR1 activation due to distorted NAB2 activity.

Virtual slides: The virtual slide(s) for this article can be found here: http://www.diagnosticpathology.diagnomx.eu/vs/ 13000_2014_224

Keywords: Solitary fibrous tumor, Hemangiopericytoma, NAB2-STAT6 fusion, RT-PCR, STAT6 immunohistochemistry, EGR1 immunohistochemistry, Soft tissue

\footnotetext{
* Correspondence: rob.vogels@radboudumc.nl

'Department of Pathology, Radboud University Medical Center, P.O. Box

9101, 6500 HB Nijmegen, The Netherlands

Full list of author information is available at the end of the article
} 


\section{Background}

Solitary fibrous tumor (SFT) is a mesenchymal tumor of fibroblastic type that can affect virtually any region of the body [1,2]. The neoplastic cells are arranged in a patternless architecture with alternating hypo- and hypercellular areas and a prominent branching vasculature. These lesions occur predominantly in middle-aged adults with equal gender distribution [1]. Most tumors present as well defined, slow growing masses, which can be cured by surgery. A small percentage of SFTs, between $10-20 \%$, behave in a more aggressive way, with local recurrence and/or distant metastasis for which systemic therapy (chemotherapy or targeted treatment with e.g. sunitinib) can be given [1,3-5]. Prediction of behavior is difficult, with tumor size above $15 \mathrm{~cm}$, positive surgical margins, tumor site and high mitotic count $(>4 / 10$ high power fields, HPF) being the most useful indicators for malignancy $[3,6-8]$.

Recently, a recurrent gene fusion NAB2-STAT6 has been identified as molecular hallmark of SFT, encoding a chimeric protein that combines the EGR-binding domain of NAB2, a repressor of early growth response (EGR) transcription factors that regulate differentiation and proliferation, with the transactivation domain of STAT6, a transcription factor that mediates cytokine signaling $[2,9]$. Molecular detection of the fusion gene and immunohistochemical expression of nuclear STAT6 can be helpful in diagnosing SFT, especially in cases not unequivocally classifiable $[2,10-13]$.

In this study, molecular analysis and immunohistochemical staining of STAT6 protein was performed in 28 cases of SFT. In addition, as the NAB2-STAT6 fusion leads to EGR1 (early growth response protein 1 ) activation and transcriptional deregulation of EGR1-dependent target genes, we immunohistochemically evaluated the expression of EGR1 in our tumor samples in order to semi-quantify EGR1 protein levels in SFT $[2,14]$.

\section{Methods}

\section{Tissue samples and immunohistochemistry}

Twenty-eight cases were selected from the (referral) files of the authors between 01-2002 and 08-2014 and slides were reviewed by two of them (UF, PS). The study was performed in accordance with the Code of Conduct of the Federation of Medical Scientific Societies in the Netherlands. The tissue was fixed in $4 \%$ buffered formalin, routinely processed and embedded in paraffin; $4 \mu \mathrm{m}$ thick sections were stained with hematoxylin and eosin and immunohistochemistry was performed using commercially available antibodies listed in Table 1.

Antigen retrieval was performed using EDTA buffer, $\mathrm{pH} 9,0$ for 10 minutes at $95^{\circ} \mathrm{C}$ and 10 minutes blocking with $3 \% \mathrm{H} 2 \mathrm{O} 2$ in methanol. The primary antibodies (dilutions presented in Table 1) were added for 1 hour
Table 1 Details of used antibodies

\begin{tabular}{llll}
\hline Antibody & Clone & Dilution & Source \\
\hline STAT6 & YE361 & $1: 80$ & ABCam, Cambridge, UK \\
EGR1 & T.160.5 & $1: 50$ & ThermoFisher Scientific, Waltham, USA \\
CD34 & QBEnd/10 & $1: 80$ & Immunologic, Duiven, the Netherlands \\
CD99 & O13 & $1: 150$ & ThermoFisher Scientific, Waltham, USA \\
EMA & E29 & $1: 250$ & DAKO, Glostrup, Denmark \\
SMA & 1A4 & $1: 30000$ & Sigma, Saint Louis, USA \\
S-100 & polyclonal & $1: 10000$ & DAKO, Glostrup, Denmark \\
BCl-2 & 124 & $1: 80$ & DAKO, Glostrup, Denmark \\
\hline
\end{tabular}

at room temperature. Secondary antibody Poly-HRP $\mathrm{Gam} / \mathrm{R} / \mathrm{Ra}$; Immunologic was applied for 30 minutes at room temperature. The chromogenic substrate Bright DAB; Immunologic was applied for 7 minutes at room temperature.

Cases were scored positive for STAT6, CD34, CD99, EMA, SMA, Bcl-2 and S100 when at least 50\% of tumor cells showed strong staining. EGR1 was scored using a six-point scale $(0=$ negative; $1=<5 \%$ nuclei $+; 2=5-25 \%$ nuclei $+; 3=26-50 \%$ nuclei $+; 4=51-75 \%$ nuclei $+; 5=$ 76-100\% nuclei + ). As (negative) control samples for STAT6 and EGR1, some possible mimickers of SFT were stained ( 5 dedifferentiated liposarcomas, 5 deep benign fibrous histiocytomas, 5 sarcomatoid mesotheliomas, 7 low grade fibromyxoid sarcomas, 5 schwannomas, 4 malignant peripheral nerve sheath tumors, 5 gasto-intestinal stroma cell tumors, 5 synovial sarcomas and 6 leiomyomas). Endothelial nuclei served as an internal positive control for EGR1. Clinical information, where available, was obtained from the hospital records.

\section{Reverse transcriptase-Polymerase chain reaction (RT-PCR)}

RNA was extracted from formalin-fixed and paraffinembedded tissues (FFPE) using RNA-Bee-RNA isolation reagent (Bio-Connect BV, Huissen, the Netherlands) according to standard procedures. RNA quantity and quality were determined by a NanoDrop measurement (Fisher Scientific, Landsmeer, the Netherlands) and subsequently, cDNA synthesis was performed using Superscript II (Invitrogen Life Technologies Europe, Bleiswijk, the Netherlands) and random hexamers (Promega Nederland, Leiden, the Netherlands).

The cDNA was tested by the reverse transcriptionpolymerase chain reaction (RT-PCR) for the HMBS (hydroxymethylbilase synthase) housekeeping gene using the primers forw150 5'-TGCCAGAGAAGAGTGTG GTG-3', rev150 5' -ATGATGGCACTGAACTCCTG-3', forw250 5' - CTGGTAACGGCAATGCGGCT-3', rev250 5' - TTCTTCTCCAGGGCATGTTC-3'.

For the detection of the NAB2-STAT6, three primers in NAB2 (NM_005967.3) exon3 forw 5' - CAAGTAGCC 
CGAGAGAGCAC-3', exon4 forw 5' - CTCCACTGAA GAAGCTGAAAC-3' and exon6 forw 5' ${ }^{\prime}$-CTGTGTGCC TGCGAAGCC-3' were used in combination with three STAT6 (NM_001178078.1) primers: rev 5'-GGGAAAG TCGACATAGAGCC-3' (exon3), rev 5'-GAGCTGAGC AAGATCCCGG-3' (exon17) and rev 5'-TTCCACGGT CATCTTGATGG-3' (exon18). The PCR products were analyzed by agarose gel electrophoresis. The sequence of the differently sized PCR-products was obtained by Sanger sequencing and confirmed presence of the fusion gene.

\section{Results}

\section{Clinical data}

Clinical data are summarized in Table 2. Twenty-eight patients were selected, including 10 male and 18 female patients with an age range of 21-84 years (median, 54 years)

Tumors arose in the lung and pleura (9,32\%), deep soft tissue of the lower extremities $(5,18 \%)$, head and neck $(5,18 \%)$, abdomen $(3,11 \%)$ and pelvis $(2,7 \%)$. Other sites were uterus, retroperitoneum, deep soft tissue of the upper extremity and deep soft tissue of the back (1 case each).

Surgical excision was performed in 28 patients, 1 after prior embolization. Resection margins were positive in 3 patients, negative in 21 patients, and not reported in 4 cases. One patient with positive margins (case 16) and a subsequent local recurrence received surgery combined with radiotherapy for his recurrent disease and had no evidence of disease at 7 months. The other 2 patients with positive resection margins did not receive post-

Table 2 Clinical data of 28 patients with SFT

\begin{tabular}{|c|c|c|c|c|c|c|c|c|c|}
\hline Case & Age & Sex & Size $(\mathrm{cm})$ & Site & Margin status & Treatment & Local recurrence & MET & Follow-up \\
\hline 1 & 21 & $\mathrm{~F}$ & 9 & Abdomen & Neg & SE & Y, multiple & Y & DOD, 52 yrs \\
\hline 2 & 74 & $\mathrm{~F}$ & 9 & Calf & Neg & SE & NA & NA & NA \\
\hline 3 & 59 & $M$ & 13 & Pelvis & Neg & SE; CT after MET & Y & Y & NED, MET 48 mo \\
\hline 4 & 55 & $\mathrm{~F}$ & 9.5 & Retro-peritoneum & Neg & $\mathrm{SE} ; \mathrm{CT}+\mathrm{RT}$ after MET & $\mathrm{N}$ & Y & DOD, $13 \mathrm{mo}$ \\
\hline 5 & 84 & $\mathrm{~F}$ & 10 & Para-tracheal & Neg & SE & NA & NA & NED, 48 mo \\
\hline 6 & 68 & $\mathrm{~F}$ & 17 & Lung & Neg & SE & NA & NA & NA \\
\hline 7 & 39 & $\mathrm{~F}$ & 3 & Thigh & Neg & SE & $\mathrm{N}$ & $\mathrm{N}$ & NED, 36 mo \\
\hline 8 & 34 & $M$ & 4.1 & Cheek & Neg & SE & $N$ & $\mathrm{~N}$ & $\mathrm{NED}, 27 \mathrm{mo}$ \\
\hline 9 & 75 & $\mathrm{~F}$ & 12 & Neck & Neg & SE & $N$ & $\mathrm{~N}$ & $\mathrm{NED}, 26 \mathrm{mo}$ \\
\hline 10 & 50 & $\mathrm{~F}$ & 10 & Uterus & Neg & SE & $\mathrm{N}$ & $\mathrm{N}$ & NED, 33 mo \\
\hline 11 & 52 & F & 4.7 & Biceps & Neg & SE & $\mathrm{N}$ & $\mathrm{N}$ & NED, 32 mo \\
\hline 12 & 52 & $M$ & 6.3 & Lung & Pos & SE & $\mathrm{N}$ & $\mathrm{N}$ & $\mathrm{NED}, 17 \mathrm{mo}$ \\
\hline 13 & 56 & $M$ & 16 & Pelvis & Neg & SE & $\mathrm{N}$ & $\mathrm{N}$ & $\mathrm{NED}, 12 \mathrm{mo}$ \\
\hline 14 & 53 & $\mathrm{~F}$ & 4.5 & Pleura & Neg & SE & $\mathrm{N}$ & $\mathrm{N}$ & $\mathrm{NED}, 21 \mathrm{mo}$ \\
\hline 15 & 71 & $M$ & NA & Lung & NA & SE & NA & NA & NA \\
\hline 16 & 39 & $M$ & 2 & Mastoid & Pos & $\begin{array}{l}\mathrm{EMB}+\mathrm{SE} ; \mathrm{SE}+\mathrm{RT} \\
\text { after recurrence }\end{array}$ & Y & $\mathrm{N}$ & $\begin{array}{l}\text { NED, } 7 \text { mo after treatment } \\
\text { of recurrent disease }\end{array}$ \\
\hline 17 & 44 & F & 2.5 & Orbit & Neg & SE & Y & $\mathrm{N}$ & NA \\
\hline 18 & 55 & $M$ & 13 & Lung & Neg & SE & $\mathrm{N}$ & $\mathrm{N}$ & NED, 9 yrs \\
\hline 19 & 63 & $M$ & 4 & Lung & Neg & SE & NA & NA & NA \\
\hline 20 & 45 & F & 7.5 & Mesenterium & Neg & SE & $\mathrm{N}$ & $\mathrm{N}$ & NED, 10 yrs \\
\hline 21 & 33 & $\mathrm{~F}$ & 9 & Calf & Pos & SE & $\mathrm{N}$ & $\mathrm{N}$ & $\mathrm{NED}, 23 \mathrm{mo}$ \\
\hline 22 & 67 & $\mathrm{~F}$ & NA & Buttock & NA & SE & $\mathrm{N}$ & $\mathrm{N}$ & NA \\
\hline 23 & 68 & F & 14 & Pleura & NA & SE & $\mathrm{N}$ & $\mathrm{N}$ & NED, 8 mo \\
\hline 24 & 76 & M & 7 & Abdomen & Neg & SE & NA & NA & NA \\
\hline 25 & 69 & F & NA & Lung & NA & SE & NA & NA & NA \\
\hline 26 & 43 & $M$ & 9.5 & Back & Neg & SE & NA & NA & NA \\
\hline 27 & 42 & F & 1.6 & Head & Neg & SE & NA & NA & NA \\
\hline 28 & 42 & $\mathrm{~F}$ & 5.5 & Knee & Neg & SE & $\mathrm{N}$ & $\mathrm{N}$ & NED, 9 yrs \\
\hline
\end{tabular}


surgical therapy and had no evidence of disease at 17 and 23 months.

Recurrences occurred in 4 instances (14\%) including 3 patients with negative margins and the above mentioned case 16 with positive margins. One of the 3 patients with negative margins (case 1) had surgical therapy for several local recurrences and metastatic disease. One patient (case 3) received surgery for local recurrence and chemotherapy after discovery of metastatic spread. Fifteen patients had no recurrences, and of 9 patients, data about local recurrences were not known.

Metastatic disease occurred in 3 patients, including case 1 and case 3 mentioned above. One patient (case 4) received combined radio-chemotherapy after discovery of metastases. Sixteen patients showed no metastatic disease and of the remaining 9 cases, data were not known.

Two patients died of metastatic disease 13 months and 52 years after the initial diagnosis (case 4 and 1, respectively). In case 1, recurrences and metastases were histologically proven.

Currently, 16 patients have no evidence of disease with a median follow up of 29.5 months (range $7-120$ months), including 3 patients with long term disease-free follow up. Ten patients were lost to follow-up or no follow-up data could be obtained.

\section{Gross findings}

Tumor size ranged from $1.6-17 \mathrm{~cm}$ (median, $9 \mathrm{~cm}$ ). Grossly, the tumors had a (multi)nodular configuration with a coarse white-grayish cut-surface. Myxoid areas were apparent in some cases.

\section{Microscopic findings}

Histologically, most of the tumors were circumscribed and a (incomplete) pseudo capsule was sometimes detected. In few cases, focal infiltration of adjacent structures was seen. All cases showed typical features of SFT with a patternless architecture of alternating hypo- and hyper cellular areas of spindle-shaped cells (Figure 1A). A round cell component was found in 2 cases (case 17 and recurrences of case 1). The latter case showed additionally a fascicular growth pattern in the recurrences. The nuclei were relatively uniform, spindled or oval-shaped. Nuclear atypia was focally obvious in case 12 and giant cells were detected in case 8 . The mitotic rate ranged from $0 / 10$ HPF to 30/10 HPF (with no differences between patients with or without metastatic disease, Table 3). Hemangiopericytoma-like vessels were visible in all cases, partly with hyalinization of the vessel walls. A variable collagenous background was existent and case 5 possessed amianthoid fibers. Pseudocystic changes were seen in myxoid areas of 5 cases and small areas of necrosis were present in 3 cases. Mature adipocytes were a component in 1 case being an example of a morphologically malignant fat-forming SFT which was published previously [15].

\section{Immunohistochemical findings}

Immunohistochemical staining results are summarized in Table 3 and Table 4. All 28 cases were stained for STAT6 and all of them showed diffuse and strong nuclear positivity (Figure 2; 28/28, 100\%). All 28 cases were stained for EGR1 (Figure 3). Most cases showed less than 25\% nuclear positivity (12/28 cases score $1,6 / 28$ cases score 2$)$. Few cases had more than $25 \%$ of all nuclei stained ( $5 / 28$ cases score 3 , $1 / 28$ cases score $4,3 / 28$ cases score 5 ). Scoring of one case was not possible due to limited available tissue. All dedifferentiated liposarcomas (0/5 pos), deep benign fibrous histiocytomas (0/5 pos), sarcomatoid mesotheliomas ( $0 / 5$ pos), low grade fibromyxoid sarcomas (0/7 pos), schwannomas (0/5 pos), malignant peripheral nerve sheath tumors $(0 / 4$ pos), gasto-intestinal stroma cell tumors $(0 / 5$ pos), synovial sarcomas ( $0 / 5$ pos) and leiomyomas ( $0 / 6$ pos) showed no nuclear staining for STAT6. EGR1 showed variable expression in the different tumor samples, as depicted in Table 4.

CD34 (Figure 1B) was positive in 24 of 25 stained cases (96\%) and CD99 in 17 of 18 stained cases (94\%). Bcl-2 showed expression in 100\% of the stained samples. EMA, SMA and S100 were negative in most of the cases

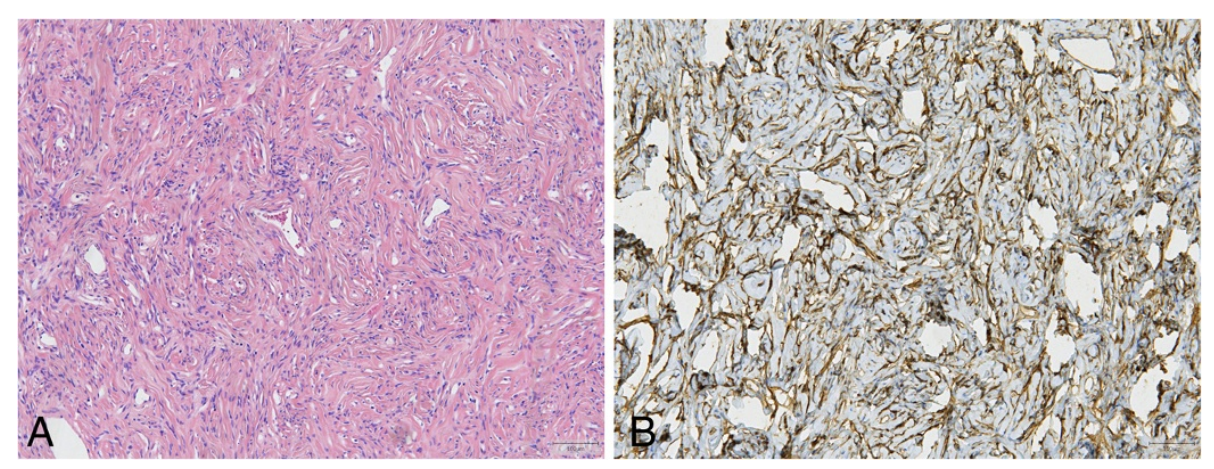

Figure 1 Typical features of SFT visible in all cases (A, HE 10x) and immunohistochemical positive staining of CD34 (B, 10x). 
Table 3 Results translocation analysis, mitotic index and immunohistochemical staining

\begin{tabular}{|c|c|c|c|c|c|c|c|c|c|c|c|}
\hline Case & Fusion & mit. & CD34 & CD99 & EMA & SMA & $\mathrm{S} 100$ & $\mathrm{BCL2}$ & STAT6 & EGR1 & Others \\
\hline 1 & Ex4-Ex3 & $8 / 10$ & + & + & - & - & - & + & + & 1 & desmine - \\
\hline 2 & Positive & $3 / 10$ & + & + & & + & + & + & + & 3 & desmine -, CK-pan - \\
\hline 3 & Ex4-Ex3 & $3 / 10$ & + & & & - & & + & + & 1 & desmine - \\
\hline 4 & Negative & $0 / 10$ & - & + & - & + & - & + & + & 1 & desmine - \\
\hline 5 & Ex4-Ex3 & $0 / 10$ & + & + & & - & - & + & + & 1 & desmine -, CK-pan - \\
\hline 6 & Ex4-Ex3 & $4 / 10$ & + & $w+$ & & & - & + & + & 2 & CK-pan + \\
\hline 7 & Negative & $1 / 10$ & + & + & - & - & - & + & + & 5 & CK-pan - \\
\hline 8 & Positive & $0 / 10$ & + & + & & - & & + & + & 2 & CK-pan - \\
\hline 9 & Ex7-Ex3 & $0 / 10$ & + & + & & & & + & + & 2 & CK-pan - \\
\hline 10 & Negative & $1 / 10$ & + & + & - & - & - & + & + & 3 & desmine -, CK-pan - \\
\hline 11 & Negative & $0 / 10$ & + & + & & - & - & + & + & 2 & desmine -, CK-pan - \\
\hline 12 & Ex4-Ex3 & $1 / 10$ & + & & & & & + & + & 4 & desmine - \\
\hline 13 & Negative & $0 / 10$ & + & + & $f+$ & - & - & + & + & 3 & desmine - \\
\hline 14 & Ex4-Ex3 & $0 / 10$ & + & + & & & & + & + & 1 & \\
\hline 15 & Ex4-Ex3 & $0 / 10$ & + & + & & - & - & $w+$ & + & NA & \\
\hline 16 & Ex6-Ex17 & $30 / 10$ & + & + & & & & + & + & 3 & desmine - \\
\hline 17 & Ex6-Ex18 & $13 / 10$ & + & + & - & & - & + & + & 1 & desmine -, CK-pan - \\
\hline 18 & Ex4-Ex3 & $0 / 10$ & + & & & - & - & + & + & 2 & desmine $\mathrm{f}+$, CK-pan - \\
\hline 19 & Ex4-Ex3 & $0 / 10$ & + & & & - & - & & + & 1 & desmine - \\
\hline 20 & Negative & $1 / 10$ & + & & & - & - & & + & 1 & desmine -, CK-pan - \\
\hline 21 & Ex6-Ex18 & $0 / 10$ & + & & & & & + & + & 1 & \\
\hline 22 & Ex6-Ex3 & $0 / 10$ & + & & & $w+$ & - & & + & 1 & desmine - \\
\hline 23 & Ex4-Ex3 & $8 / 10$ & + & + & & - & - & + & + & 1 & desmine - \\
\hline 24 & Negative & $1 / 10$ & + & + & & & & + & + & 3 & desmine -, CK-pan - \\
\hline 25 & Ex4-Ex3 & $1 / 10$ & + & & & & & & + & 1 & \\
\hline 26 & NA & $0 / 10$ & + & & & & & & + & 5 & \\
\hline 27 & Ex6-Ex18 & $0 / 10$ & + & & & & & & + & 2 & \\
\hline 28 & NA & $6 / 10$ & + & - & & & - & & + & 5 & desmine -, CK-pan - \\
\hline
\end{tabular}

Mit., mitotic figures/10 HPF; $w+$, weakly positive; $f+$, focally positive; $N A=$ not assessable EGR1: $0=$ negative; $1=<5 \%$ nuclei $+; 2=5-25 \%$ nuclei $+; 3=26-50 \%$ nuclei $+; 4=51-75 \%$ nuclei $+; 5=76-100 \%$ nuclei + .

Fusion-positive cases are characterized by exon junctions, except for case 8 showing a complex junction indicated as positive; negative, no fusion detected.

Table 4 Immunohistochemical staining results control samples

\begin{tabular}{lll}
\hline Soft tissue tumor & EGR1 & STAT6 (pos/total (\%)) \\
\hline Dedifferentiated liposarcoma & $1,2,3,3,3$ & $0 / 5(0 \%)$ \\
Low grade fibromyxoid sarcoma & $1,2,2,2,2,3,3$ & $0 / 7(0 \%)$ \\
Deep benign fibrous histiocytoma & $3,4,4,4,4$ & $0 / 5(0 \%)$ \\
$\begin{array}{l}\text { Malignant peripheral nerve } \\
\text { sheath tumor }\end{array}$ & $2,2,3,4$ & $0 / 4(0 \%)$ \\
(Sarcomatoid) mesothelioma & $1,2,2,3,3$ & $0 / 5(0 \%)$ \\
Schwannoma & $2,3,3,3,4$ & $0 / 5(0 \%)$ \\
Gastro-intestinal stroma cell tumor & $2,3,3,4,4$ & $0 / 5(0 \%)$ \\
Synovial sarcoma & $2,3,3,3,4$ & $0 / 5(0 \%)$ \\
Leiomyoma & $1,1,2,2,2,3$ & $0 / 6(0 \%)$ \\
\hline
\end{tabular}

(83\%, $80 \%$ and $94 \%$, respectively). One case each was (at least focally) positive for pan-keratin and desmin (Table 3).

\section{Molecular genetics findings}

Results of molecular analysis are summarized in Table 3. NAB2-STAT6 fusion transcripts were found in 19/28 cases (68\%). Most fusions occurred between $N A B 2$ exon 4 and STAT6 exon $3(11 / 19,58 \%$; Figure 4$)$. Nine of them were detected in lung and pleura lesions. Three cases (16\%) had the isoform NAB2 exon 6 with STAT6 exon 18. Two of them were located in the head and neck region. Single cases showed fusion variants of $N A B 2$ exon 6 and STAT6 exon 17, NAB2 exon 7 and STAT6 exon 3 and NAB2 exon 6 and STAT6 exon 3. Two tumors (case 2 and case 8) harbored a fusion, but due to complex 


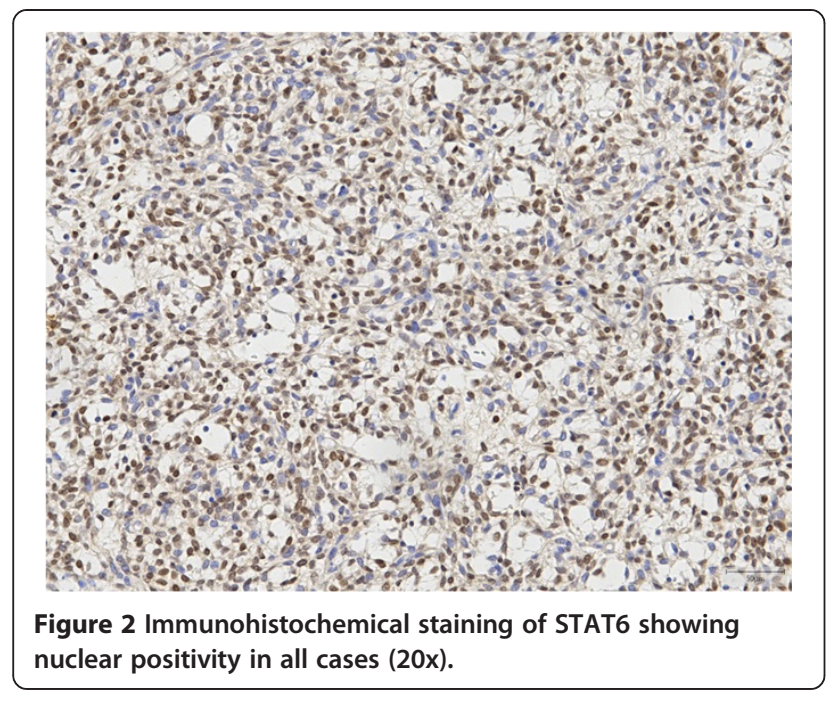

breakpoints with a possible inversion the exact exons could not be verified. In 7 tumors, no NAB2-STAT6 fusion was found $(7 / 28,25 \%)$. In case 26 and case 28 , adequate interpretation of RT-PCR results was not possible due to the presence of complex breakpoints.

\section{Discussion}

In 1942 and 1949, Stout and Murray defined hemangiopericytoma as a neoplasm with prominent branching vessels surrounded by pericytic tumor cells $[16,17]$. The lesions included in their studies comprised true pericytic tumors, nowadays termed myofibroma/myopericytoma, and conventional hemangiopericytoma, which was afterwards accepted as cellular variant of SFT [18]. The unified entity SFT now also contains the lipomatous variant, giant cell angiofibroma, and at the malignant end, dedifferentiated SFT showing abrupt transition from classical areas into high-grade sarcoma [1].

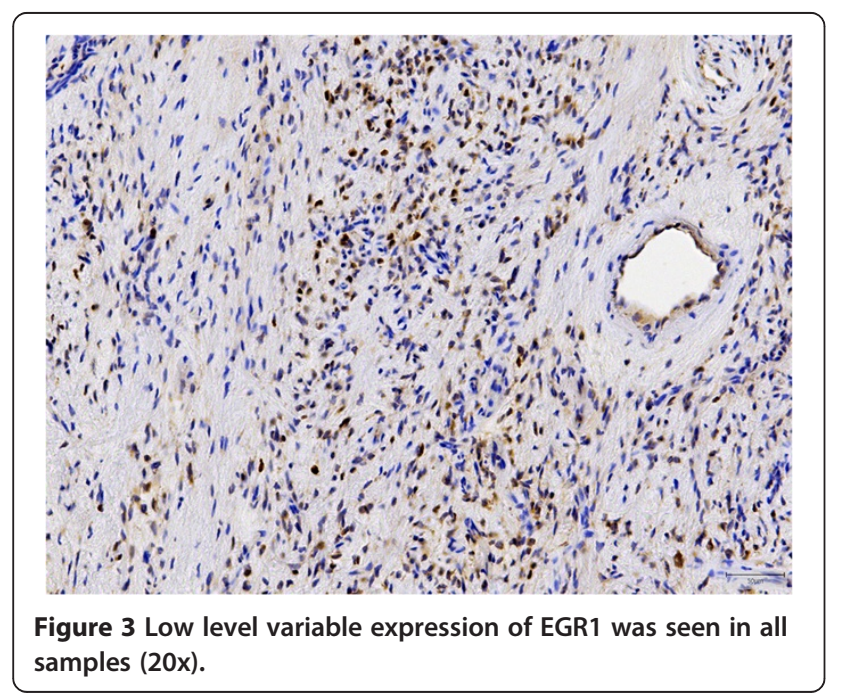

With the advent of whole-genome sequencing, the fusion gene NAB2-STAT6 has been detected as the driver mutation of SFT $[2,9,10,14]$. NAB2 and STAT6, adjacent genes on 12q13, fuse following genomic inversion of STAT6 with consecutive transcription in a common direction [2,9]. Expression of the chimeric protein NAB2STAT6 leads to activation of EGR-mediated signaling via distorted NAB2 activity. Modulation of STAT6 dependent gene expression seems to be an alternative mechanism but was shown to play a minor role [2,9].

NAB2-STAT6 fusion is a distinct molecular feature of SFT since it has not been detected in other tumors (so far) and its frequency ranges from 55\% to $100 \%$, irrespective of dignity $[2,9,13,14]$. There are several fusion variants, with conjunction of NAB2 exon 4 - STAT6 exon 3 and NAB2 exon 6- STAT6 exon 17 being the most common $[2,13,14]$. In our study, $68 \%$ of SFTs carried a NAB2-STAT6 fusion transcript, mostly with a fusion between NAB2 exon 4 and STAT6 exon 3 in accordance with the results by Mohajeri et al. and Barthelmess et al. $[13,14]$. Negativity for this fusion in $25 \%$ of our cases could possibly be explained by alternative or complex genetic rearrangements involving other exons or inversions and deletions, not detectable with our primer combination. In 2 cases (7\%), adequate interpretation of RT-PCR results was not possible due to the presence of complex breakpoints. Furthermore, in single cases other fusion genes have been reported, e.g. STAT6-TRAPPC5 [14] and probably additional fusion genes will be detected in the future.

Doyle et al. demonstrated nuclear expression of STAT6 in $98 \%$ of a large series of SFTs indicating the presence of the NAB2-STAT6 fusion protein in the nucleus [11]. STAT6 is therefore a highly sensitive and specific immunohistochemical marker for SFT [10-13,19,20]. This is in concert with our results, where $100 \%$ of the cases showed strong and diffuse nuclear positivity for STAT6 in comparison to the control group being 100\% negative. Thereby, STAT6 was diffusely expressed in 7 tumors without a detected NAB2-STAT6 fusion, suspecting limitations in our RT-PCR approach in which NAB2-STAT6 fusions could be missed as mentioned above. Potential diagnostic pitfalls could be STAT6 expression in, for example, the morphologic mimics deep benign fibrous histiocytoma and dedifferentiated liposarcoma, especially in retroperitoneal and abdominal localization [11]. As known, MDM2 and CDK4 immunohistochemistry or MDM2 FISH are useful in identifying dedifferentiated liposarcoma. Expression of STAT6 in ca. 10\% of dedifferentiated liposarcomas is based on amplification of the corresponding gene located in proximity to $M D M 2$ and $C D K 4[11,12,21,22]$. Deep benign fibrous histiocytoma may also show a hemangiopericytoma-like vasculature and may express CD34 [1]. In such cases, molecular analysis of NAB2-STAT6 may be helpful. 


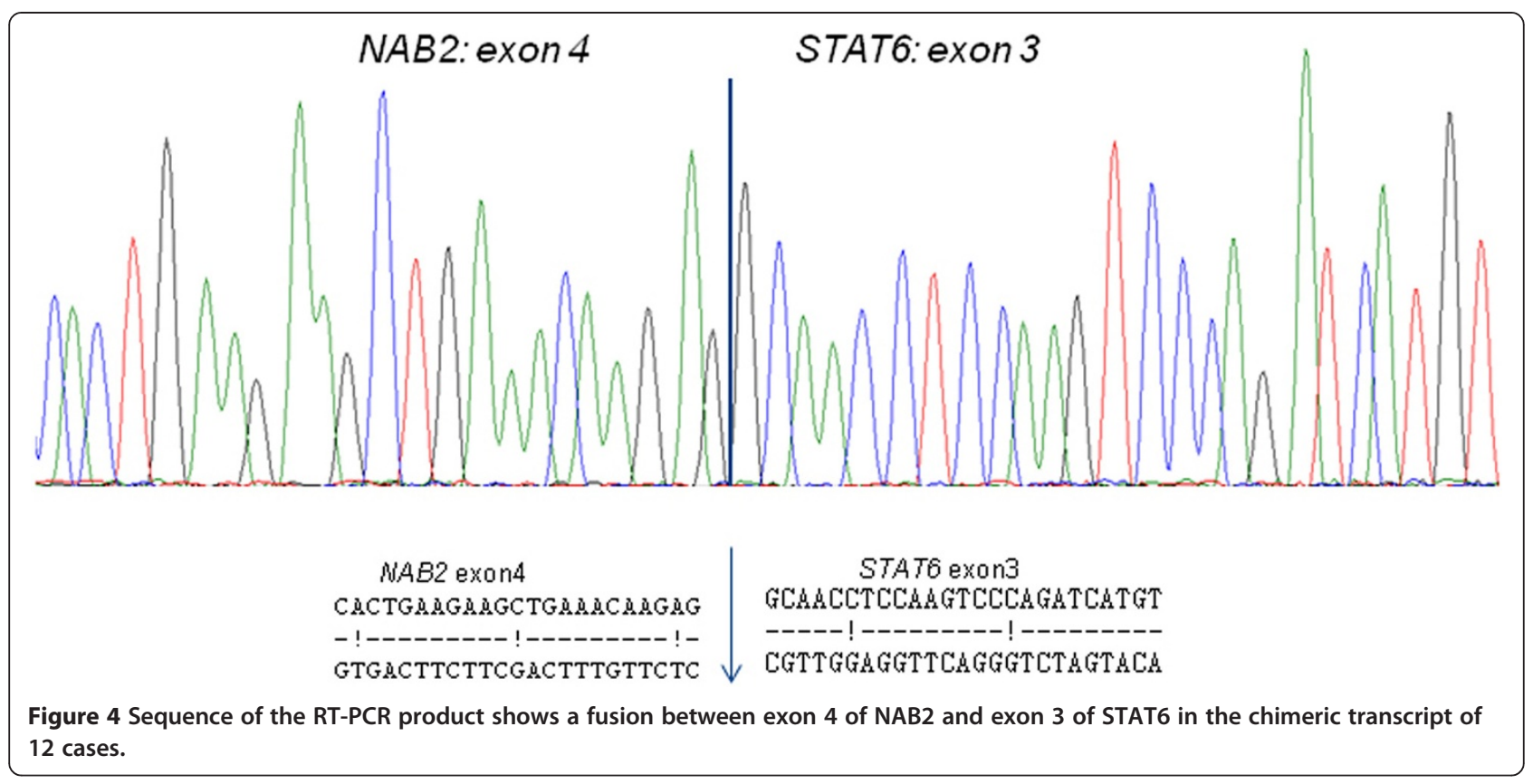

Other differential diagnoses and their histopathological characteristics are listed in Table 5.

Previously, CD34, CD99 and bcl-2 were the most useful positive immunohistochemical markers for SFT. However, they are less specific and absence of CD34 does not rule out SFT [1,28-31].

As expected, CD34, CD99 and bcl-2 were positive in most of our cases. Case 4 with negative staining for CD34 and absence of a detectable gene fusion showed strong nuclear expression of STAT6 and no MDM2 amplification, so the possibility of being a dedifferentiated liposarcoma was ruled out.

Cell line experiments supported that in contrast to the known transcriptional repressor activity of NAB2, the NAB2-STAT6 fusion protein leads to activation of EGR1 and expression of its target genes. In addition, the increased proliferation of the NAB-STAT6-expressing cell lines could be inhibited by small interfering RNA (siRNA) knockdown of EGR1 expression [2]. This prompted us to investigate EGR1 protein expression in our tumor samples which showed low-level variable nuclear reactivity in all stained samples, including 47 control samples of possible mimickers of SFT. This result is in line with EGR1 protein activation without high-level expression mainly due to altered NAB2 function resulting in deregulation of target genes as mentioned above $[2,14]$.

Correlation of clinicopathologic parameters and outcome is difficult. This could be due to, at least in part, relatively small cohorts of SFT studied. Therefore, no statistical correlation could be made between pathological findings and clinical data. To date, no definitive markers have been identified that classify malignant SFT. Recently, efforts have been made to define a risk assessment model based on patient age, tumor size and mitotic index with promising results $[7,8]$. From the genetic point of view, Mohajeri et al. [14] did not find any clinical associations including genetic changes beyond the fusion-genes. In contrast, Barthelmess et al. showed that the most common fusion variant NAB2 exon 4-STAT6 exon 3 corresponded to classic pleuropulmonary SFT as we found in our study: all 9 pleuropulmonary SFTs had a fusion between NAB2 exon 4 and STAT6 exon 3.

NAB2 exon 6-STAT6 exon16/17 fusions were detected in cellular soft tissue SFTs with more aggressive behavior in younger patients [13].

Three of the 18 patients (17\%) of whom we had adequate clinical follow-up data (cases $1,3,4$ ) behaved in a malignant fashion with metastases. Only one of them showed a high mitotic index (case 1). Locations were abdomen, pelvis and retroperitoneum in accordance with known parameters for malignant potential but sizes were below $10 \mathrm{~cm}$ [6-8].

Therapeutic options for more advanced or aggressive tumors are scarce and no standard modality for metastasized SFT has currently been accepted. Few chemotherapeutical drugs have been studied with different outcome. Anti-angiogenic targeted treatment shows interesting results $[4,5]$. The potential role of EGR1 and its downstream targets in treatment of (metastasized SFT) is not clearly defined so far $[2,9]$. 
Table 5 Differential diagnoses of SFT (in accordance with Fletcher et al. and Doyle et al. [1,11])

\begin{tabular}{|c|c|c|c|}
\hline & Histopathological characteristics & IHC & Genetic alterations \\
\hline \multirow[t]{2}{*}{ Dedifferentiated liposarcoma } & lipogenic component with atypia & $\mathrm{MDM} 2+, \mathrm{CDK} 4+$ & amplification MDM2 \\
\hline & atypia in dediff. component can be mild & STAT6 -/+ & \\
\hline Deep benign fibrous histiocytoma & $\begin{array}{l}\text { storiform or short fascicles, } \\
\text { branching vasculature }\end{array}$ & $\begin{array}{l}\text { CD34 +/-, SMA f+/-, } \\
\text { STAT6 }-/+\end{array}$ & \\
\hline \multirow[t]{2}{*}{ Spindle cell lipoma } & short stubby nuclei, ropey collagen & CD34+ & RB1deletion \\
\hline & variable proportions of fat & & \\
\hline \multirow[t]{2}{*}{ Cellular angiofibroma } & short stubby nuclei, wispy collagen & CD34 +/-, desmin -/+ & RB1 deletion \\
\hline & numerous (hyalinized) vessels & SMA -/+, & \\
\hline \multirow[t]{2}{*}{ Mammary type myofibroblastoma } & (long) fascicles, short stubby nuclei & CD34 +, desmin + & RB1 deletion \\
\hline & broad bands collagen & SMA -/+, & \\
\hline Myofibroma & $\begin{array}{l}\text { biphasic, immature spindle cells and } \\
\text { mature myoid cells, bluish matrix, } \\
\text { branching vessels }\end{array}$ & $\begin{array}{l}\text { SMA }+/- \text {, desmin }-/+ \\
\text { CD34 }-/+\end{array}$ & \\
\hline Dermatofibrosarcoma protuberans & $\begin{array}{l}\text { storiform, short fascicles, uniform spindle cells, } \\
\text { "honeycomb" appearance of fat }\end{array}$ & $\mathrm{CD} 34+$ & COL1A1-PDGFB \\
\hline Monophasic synovial sarcoma & cellular fascicles, uniform spindle cells & TLE1 +, EMA +, CK + & SYT-SSX1/2 \\
\hline \multirow[t]{2}{*}{ Cellular schwannoma } & short bundles, interlacing fascicles & $\mathrm{S} 100+$ & NF2 mutations \\
\hline & tapered nuclei, hyalinized (ectatic) vessels & & \\
\hline Perineurioma & $\begin{array}{l}\text { storiform, whorled growth, bipolar cells, } \\
\text { uniform oval or tapering nuclei }\end{array}$ & $\begin{array}{l}\text { CD34 +/-, EMA +, } \\
\text { Claudin-1-/+, GLUT1 -/+ }\end{array}$ & \\
\hline Low-grade fibromyxoid sarcoma & $\begin{array}{l}\text { alternating hypo- and more cellular } \\
\text { fascicles and whorls, fibrous and myxoid } \\
\text { background, bland spindle cells }\end{array}$ & MUC4 +, EMA + & FUS-CREB3L1/2 \\
\hline \multirow[t]{2}{*}{ Inflammatory myofibroblastic tumor } & fascicles of myofibroblasts, myxoid or & $\mathrm{SMA}+/-$, desmin $+/-$ & $A L K$ rearrangement $+/-$ \\
\hline & collagenous background, inflammation & $\mathrm{ALK}+/-$ & \\
\hline Sarcomatoid mesothelioma & $\begin{array}{l}\text { fascicles or haphazard distribution, } \\
\text { atypical spindle cells }\end{array}$ & CK, EMA, D2-40, caretinin, WT1 & BAP1 mutation [23] \\
\hline Inflammatory fibroid polyp & onion-skin pattern, short fascicles & CD34 +/- & PDGFRA mutation \\
\hline of the GI tract [24] cells, & $\begin{array}{l}\text { prominent vasculature, inflammatory } \\
\text { especially eosinophils }\end{array}$ & & \\
\hline \multirow[t]{2}{*}{ Soft tissue angiofibroma [25] } & variably collagenous and myxoid areas & $\mathrm{EMA}+/-, \mathrm{CD} 34-/+$ & GTF2I-NCOA2 [26] \\
\hline & numerous small branching capillaries & & AHRR-NCOA2 [27] \\
\hline
\end{tabular}

\section{Conclusions}

In summary, STAT6 immunohistochemistry is a powerful tool in diagnosing SFTs. Also, the identification of the NAB2-STAT6 fusion gene can provide important diagnostic information, even in formalin-fixed and paraffin-embedded tissue or when biopsy material is limited. In accordance with Barthelmess et al., the most common fusion variant NAB2 exon 4-STAT6 exon 3 corresponded mostly to pleuropulmonary SFT.

EGR1 immunohistochemistry indicates low-level protein expression in accordance with EGR1 activation due to distorted NAB2 activity resulting in deregulation of EGR1 target genes.

\section{Competing interests}

The authors declare that they have no competing interests.

\section{Authors' contributions}

UF, PG, RV designed the study. PG, MaV, ML carried out the experiments. RV, UF, PG drafted the manuscript. MyV, YV, ER, EB, JB, WG, PA, AS contributed cases/ case information and participated in data analysis. All authors approved the final version of the manuscript.

\section{Acknowledgments}

We are grateful to Professor C.D.M. Fletcher, Brigham and Women's Hospital, Boston, MA, USA for confirming the diagnosis in 3 cases (Cases 2, 4 and 13).

\section{Author details}

${ }^{1}$ Department of Pathology, Radboud University Medical Center, P.O. Box 9101, 6500 HB Nijmegen, The Netherlands. ${ }^{2}$ Department of Medical Oncology, Radboud University Medical Center, Nijmegen, The Netherlands. ${ }^{3}$ Department of Pathology, Rijnstate Hospital, Arnhem, The Netherlands. ${ }^{4}$ Department of Surgical Oncology, Radboud University Medical Center, Nijmegen, The Netherlands. 'Department of Pathology, University Medical Center Groningen, University of Groningen, Groningen, The Netherlands. 
Received: 6 September 2014 Accepted: 11 November 2014 Published online: 29 November 2014

\section{References}

1. Fletcher CDM, World Health Organization, International Agency for Research on Cancer: WHO classification of tumours of soft tissue and bone. 4th edition. Lyon: IARC Press; 2013.

2. Robinson DR, Wu YM, Kalyana-Sundaram S, Cao X, Lonigro RJ, Sung YS, Chen CL, Zhang L, Wang R, Su F, lyer MK, Roychowdhury S, Siddiqui J, Pienta KJ, Kunju LP, Talpaz M, Mosquera JM, Singer S, Schuetze SM, Antonescu CR, Chinnaiyan AM: Identification of recurrent NAB2-STAT6 gene fusions in solitary fibrous tumor by integrative sequencing. Nat Genet 2013, 45:180-185.

3. Gold JS, Antonescu CR, Hajdu C, Ferrone CR, Hussain M, Lewis JJ, Brennan MF, Coit DG: Clinicopathologic correlates of solitary fibrous tumors. Cancer 2002, 94:1057-1068.

4. Stacchiotti S, Marrari A, Dei Tos AP, Casali PG: Targeted Therapies in Rare Sarcomas: IMT, ASPS, SFT, PEComa, and CCS. Hematol Oncol Clin North Am 2013, 27:1049-1061.

5. Stacchiotti S, Libertini M, Negri T, Palassini E, Gronchi A, Fatigoni S, Poletti P, Vincenzi B, Dei Tos AP, Mariani L, Pilotti S, Casali PG: Response to chemotherapy of solitary fibrous tumour: a retrospective study Eur J Cancer 2013, 49:2376-2383.

6. van Houdt WJ, Westerveld CM, Vrijenhoek JE, van Gorp J, van Coevorden F, Verhoef $C$, van Dalen T: Prognosis of solitary fibrous tumors: a multicenter study. Ann Surg Oncol 2013, 20:4090-4095.

7. Doyle LA, Fletcher CD: Predicting behavior of solitary fibrous tumor: Are We getting closer to more accurate risk assessment? Ann Surg Oncol 2013, 20:4055-4056.

8. Demicco EG, Park MS, Araujo DM, Fox PS, Bassett RL, Pollock RE, Lazar AJ, Wang WL: Solitary fibrous tumor: a clinicopathological study of 110 cases and proposed risk assessment model. Mod Pathol 2012, 25:1298-1306.

9. Chmielecki J, Crago AM, Rosenberg M, O'Connor R, Walker SR, Ambrogio L, Auclair D, McKenna A, Heinrich MC, Frank DA, Meyerson M: Whole-exome sequencing identifies a recurrent NAB2-STAT6 fusion in solitary fibrous tumors. Nat Genet 2013, 45:131-132.

10. Schweizer L, Koelsche C, Sahm F, Piro RM, Capper D, Reuss DE, Pusch S, Habel A, Meyer J, Gock T, Jones DT, Mawrin C, Schittenhelm J, Becker A, Heim S, Simon M, Herold-Mende C, Mechtersheimer G, Paulus W, König R, Wiestler OD, Pfister SM, von Deimling A: Meningeal hemangiopericytoma and solitary fibrous tumors carry the NAB2-STAT6 fusion and can be diagnosed by nuclear expression of STAT6 protein. Acta Neuropathol 2013, 125:651-658.

11. Doyle LA, Vivero M, Fletcher CD, Mertens F, Hornick JL: Nuclear expression of STAT6 distinguishes solitary fibrous tumor from histologic mimics. Mod Pathol 2013, 27:390-395.

12. Koelsche $C$, Schweizer $L$, Renner M, Warth A, Jones DT, Sahm F, Reuss DE, Capper D, Knosel T, Schulz B, Petersen I, Ulrich A, Renker EK, Lehner B, Pfister SM, Schirmacher P, von Deimling A, Mechtersheimer G: Nuclear relocation of STAT6 reliably predicts NAB2/STAT6 fusion for the diagnosis of Solitary Fibrous Tumour. Histopathology 2014, 65:613-622.

13. Barthelmess S, Geddert H, Boltze C, Moskalev EA, Bieg M, Sirbu H, Brors B, Wiemann S, Hartmann A, Agaimy A, Haller F: Solitary fibrous tumors/ hemangiopericytomas with different variants of the NAB2-STAT6 gene fusion are characterized by specific histomorphology and distinct clinicopathological features. Am J Pathol 2014, 184:1209-1218.

14. Mohajeri A, Tayebwa J, Collin A, Nilsson J, Magnusson L, von Steyern FV, Brosjo O, Domanski HA, Larsson O, Sciot R, Debiec-Rychter M, Hornick JL, Mandahl N, Nord KH, Mertens F: Comprehensive genetic analysis identifies a pathognomonic NAB2/STAT6 fusion gene, nonrandom secondary genomic imbalances, and a characteristic gene expression profile in solitary fibrous tumor. Genes Chromosomes Cancer 2013, 52:873-886.

15. Lee JC, Fletcher CDM: Malignant Fat-Forming Solitary Fibrous Tumor (so-called "Lipomatous Hemangiopericytoma"): Clinicopathologic Analysis of 14 Cases. Am J Surg Pathol 2011, 35:1177-1185.

16. Stout AP, Murray MR: Hemangiopericytoma: a vascular tumor featuring Zimmermann's pericytes. Ann Surg 1942, 116:26-33.

17. Stout AP: Hemangiopericytoma; a study of 25 cases. Cancer 1949, 2:1027-1054. illust.

18. Gengler C, Guillou L: Solitary fibrous tumour and haemangiopericytoma: evolution of a concept. Histopathology 2006, 48:63-74.
19. Yoshida A, Tsuta K, Ohno M, Yoshida M, Narita Y, Kawai A, Asamura H, Kushima R: STAT6 immunohistochemistry is helpful in the diagnosis of solitary fibrous tumors. Am J Surg Pathol 2014, 38:552-559.

20. Cheah AL, Billings SD, Goldblum JR, Carver P, Tanas MZ, Rubin BP: STAT6 rabbit monoclonal antibody is a robust diagnostic tool for the distinction of solitary fibrous tumour from its mimics. Pathology 2014, 46:389-395

21. Doyle LA, Tao D, Marino-Enriquez A: STAT6 is amplified in a subset of dedifferentiated liposarcoma. Mod Pathol 2014, 27:1231-1237.

22. Creytens D, Libbrecht L, Ferdinande L: Nuclear Expression of STAT6 in Dedifferentiated Liposarcomas With a Solitary Fibrous Tumor-like Morphology: A Diagnostic Pitfall. Applied Immunohistochemistry \& Molecular Morphology : AIMM 2014.

23. Zauderer MG, Bott M, McMillan R, Sima CS, Rusch V, Krug LM, Ladanyi M: Clinical characteristics of patients with malignant pleural mesothelioma harboring somatic BAP1 mutations. J Thorac Oncol 2013, 8:1430-1433.

24. Liu TC, Lin MT, Montgomery EA, Singhi AD: Inflammatory fibroid polyps of the gastrointestinal tract: spectrum of clinical, morphologic, and immunohistochemistry features. Am J Surg Pathol 2013, 37:586-592.

25. Marino-Enriquez A, Fletcher CD: Angiofibroma of soft tissue: clinicopathologic characterization of a distinctive benign fibrovascular neoplasm in a series of 37 cases. Am J Surg Pathol 2012, 36:500-508.

26. Arbajian E, Magnusson L, Mertens F, Domanski HA, Vult von Steyern F, Nord KH: A novel GTF21/NCOA2 fusion gene emphasizes the role of NCOA2 in soft tissue angiofibroma development. Genes Chromosomes Cancer 2013, 52:330-331

27. Jin $Y$, Moller E, Nord KH, Mandahl N, Von Steyern FV, Domanski HA, Marino-Enriquez A, Magnusson L, Nilsson J, Sciot R, Fletcher CD, Debiec-Rychter M, Mertens F: Fusion of the AHRR and NCOA2 genes through a recurrent translocation $\mathrm{t}(5 ; 8)(\mathrm{p} 15 ; \mathrm{q} 13)$ in soft tissue angiofibroma results in upregulation of aryl hydrocarbon receptor target genes. Genes Chromosomes Cancer 2012, 51:510-520.

28. Chilosi M, Facchettti F, Dei Tos AP, Lestani M, Morassi ML, Martignoni G, Sorio C, Benedetti A, Morelli L, Doglioni C, Barberis M, Menestrina F, Viale G: bcl-2 expression in pleural and extrapleural solitary fibrous tumours. J Pathol 1997, 181:362-367.

29. Hasegawa T, Matsuno Y, Shimoda T, Hirohashi S, Hirose T, Sano T: Frequent expression of bcl-2 protein in solitary fibrous tumors. Jpn J Clin Oncol 1998, 28:86-91.

30. Mosquera JM, Fletcher CD: Expanding the spectrum of malignant progression in solitary fibrous tumors: a study of 8 cases with a discrete anaplastic component-is this dedifferentiated SFT? Am J Surg Pathol 2009, 33:1314-1321.

31. Kayser K, Trott J, Bohm G, Huber M, Kaltner H, Andre S, Gabius HJ: Localized fibrous tumors (LFTs) of the pleura: clinical data, asbestos burden, and syntactic structure analysis applied to newly defined angiogenic/growthregulatory effectors. Pathol Res Pract 2005, 201:791-801.

doi:10.1186/s13000-014-0224-6

Cite this article as: Vogels et al: Solitary fibrous tumor - clinicopathologic, immunohistochemical and molecular analysis of 28 cases. Diagnostic Pathology 2014 9:224.

\section{Submit your next manuscript to BioMed Central and take full advantage of:}

- Convenient online submission

- Thorough peer review

- No space constraints or color figure charges

- Immediate publication on acceptance

- Inclusion in PubMed, CAS, Scopus and Google Scholar

- Research which is freely available for redistribution 